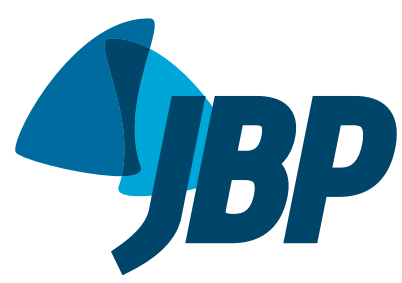

1. Departamento de Fisioterapia, Universidade Federal dos Vales do Jequitinhonha e Mucuri - UFVJM Diamantina (MG) Brasil.

2. Programa de Pós-Graduação em Reabilitação e Desempenho Funcional, Universidade Federal dos Vales do Jequitinhonha e Mucuri - UFVJM Diamantina (MG) Brasil.

3. Programa de Pós-Graduação em Ciências da Reabilitação, Universidade Federal de Minas Gerais, Belo Horizonte (MG) Brasil.

4. Departamento de Fisioterapia, Universidade Federal de Minas Gerais, Belo Horizonte (MG) Brasil.

5. School of Physical and Occupational Therapy, McGill University, Montreal, Quebec, Canada.

6. Respiratory Epidemiology and Clinical Research Unit, Research Institute of MacGill University Health Center Montreal, Quebec, Canada.

a. (iD) http://orcid.org/0000-0002-0349-3248

b. iD http://orcid.org/0000-0002-4406-081X

c. (iD) http://orcid.org/0000-0003-0944-3791

d. (iD) http://orcid.org/0000-0001-9047-7555

e. iD http://orcid.org/0000-0001-5102-369X

f. iD http://orcid.org/0000-0002-2352-8954

Submitted: 3 November 2017. Accepted: 2 March 2018.

Study carried out in the Laboratório de Avaliação e Pesquisa em Desempenho Cardiorrespiratório - LABCARE -

Universidade Federal de Minas Gerais, Belo Horizonte (MG) Brasil.

\section{Reference values for the six-minute pegboard and ring test in healthy adults in Brazil}

\author{
Vanessa Pereira Lima ${ }^{1,2, a}$, Fabiana Damasceno Almeida ${ }^{3,4, b}$, \\ Tania Janaudis-Ferreira ${ }^{5,6, c}$, Bianca Carmona ${ }^{3,4, d}$, \\ Giane Amorim Ribeiro-Samora ${ }^{3,4, e}$, Marcelo Velloso $0^{3,4, f}$
}

\begin{abstract}
Objective: To determine reference values for the six-minute pegboard and ring test (6PBRT) in healthy adults in Brazil, correlating the results with arm length, circumference of the upper arm/forearm of the dominant arm, and the level of physical activity. Methods: The participants (all volunteers) performed two 6PBRTs, 30 min apart. They were instructed to move as many rings as possible in six minutes. The best test result was selected for data analysis. Results: The sample comprised 104 individuals, all over 30 years of age. Reference values were reported by age bracket. We found that age correlated with 6PBRT results. The number of rings moved was higher in the 30 - to 39year age group than in the $>80$-year age group ( $430.25 \pm 77.00$ vs. $265.00 \pm 65.75$ ), and the difference was significant $(p<0.05)$. The 6PBRT results showed a weak, positive correlation with the level of physical activity $(r=0.358 ; p<0.05)$ but did not correlate significantly with any other variable studied. Conclusions: In this study, we were able to determine reference values for the 6PBRT in healthy adults in Brazil. There was a correlation between 6PBRT results and age.
\end{abstract}

Keywords: Upper extremity; Physical endurance; Exercise tolerance; Exercise test.

\section{INTRODUCTION}

Arm activities, whether supported or unsupported, are common when performing activities of daily living (ADLs), such as combing hair, shaving, brushing teeth, doing the dishes, or putting groceries on shelves. Previous studies have demonstrated that simple arm raising movements result in increased metabolic demand in healthy individuals $^{(1)}$ and can also increase activation of the sternocleidomastoid muscle, resulting in respiratory muscle asynchrony in activities such as combing hair. ${ }^{(2)}$ However, individuals who already have a chronic disease, such as COPD, heart disease, etc., can experience increased demand during arm activities, especially during unsupported arm activities. ${ }^{(3-5)}$ As such, various tests have been developed to evaluate strength, endurance, and exercise capacity in this population. ${ }^{(6-8)}$ One of the tests that mimics ADLs is the six-minute pegboard and ring test (6PBRT), ${ }^{(7)}$ which, with the purpose of better adaptation to Portuguese and greater dissemination of the test, was translated as "Teste de Argolas de seis minutos". The 6PBRT is a simple, inexpensive test that evaluates both arm function and endurance. ${ }^{(9)}$ It is time-limited (six minutes), validated, and reproducible, not only for individuals with $\mathrm{COPD}^{(7)}$ but also for healthy adults. ${ }^{(10)}$ Various studies have used the 6PBRT as a way to evaluate individuals with $\operatorname{COPD}^{(11,12)}$ or as a way to compare them with healthy

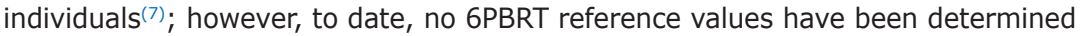
for healthy individuals in Brazil. Knowledge of reference values for a test in healthy individuals is very important, because it will enable quantification of arm impairment in subjects with a disease and comparison of results, as well as assessment of the results of therapeutic interventions, especially in rehabilitation programs.

Given the above, the objective of the present study was to determine reference values for the 6PBRT in healthy adults in Brazil, correlating the results with arm length, upper arm circumference of the dominant arm, forearm circumference of the dominant arm, and the level of physical activity.

Correspondence to:

Vanessa Pereira Lima. Campus JK, Rodovia MGT 367, km 583, 5000, Alto da Jacuba, CEP 39100-00, Diamantina, MG, Brasil.

Tel.: 5538 3532-8994. E-mail: vanessa.lima@ufvjm.edu.br

Financial support: This study received financial support from the Brazilian Conselho Nacional de Desenvolvimento Cientifico e Tecnológico (CNPq, National

Council for Scientific and Technological Development). 


\section{METHODS}

This was a prospective cross-sectional study of a convenience sample of healthy adults recruited within the internal and external community of the Federal University of Minas Gerais, located in the city of Belo Horizonte, Brazil, using data obtained between 2014 and 2016. The inclusion criteria were as follows: being 30 years of age or older; being either male or female; having no history of chronic disease; having no limitation of shoulder or arm movement that could compromise performance on the test; and having no history of symptomatic heart or lung disease. The exclusion criteria were as follows: having recently undergone a surgical procedure that prevented performance of the proposed protocol; and having a body mass index < $18.5 \mathrm{~kg} / \mathrm{m}^{2}$ or $>40 \mathrm{~kg} / \mathrm{m}^{2}$.

The study was conducted in the Federal University of Minas Gerais Laboratory for Research on and Evaluation of Cardiorespiratory Performance and was approved by the local research ethics committee (CAAE no. 47887415.6.0000.5149). All participants gave written informed consent.

\section{Initial evaluation}

Anthropometric and demographic data were collected before the start of the test session.

\section{Upper arm circumference of the dominant arm and forearm circumference of the dominant arm}

Upper arm circumference of the dominant arm and forearm circumference of the dominant arm were measured with a tape measure. The participants were asked to extend their dominant arm (defined as the arm used for signing the consent form), with the palm upward. (13) Upper arm circumference was measured midway between the acromion and olecranon, and forearm circumference was measured near the olecranon, at its point of largest diameter, with the arm relaxed at the side of the body. ${ }^{(14)}$

\section{Pulmonary function testing}

Spirometry was performed with a $\mathrm{KokO}^{\circledR}$ spirometer (PDS Instrumentation Inc., Louisville, CO, USA), in accordance with the Brazilian Thoracic Association criteria for acceptability, reproducibility, and quality, ${ }^{(15)}$ the set of values predicted for the Brazilian population being used as a reference. ${ }^{(16)}$

\section{Human Activity Profile (HAP) questionnaire}

The HAP, which has been validated and cross-culturally adapted for use in Brazil, (17) is a 94-item questionnaire addressing common ADLs that are scored according to the energy expenditure required to perform them. The items with lower values represent activities requiring less energy expenditure, and those with higher values represent activities requiring greater energy expenditure. The level of physical activity of individuals is classified by calculating the adjusted activity score (AAS), resulting in their being classified as inactive or debilitated (AAS < 53 points), moderately active (AAS between 53 and 74 points), or active (AAS > 74 points). ${ }^{(17)}$

\section{PBRT}

The 6PBRT was performed as described by Zhan et al. ${ }^{(7)}$ The participants (all volunteers) remained seated in front of a wooden board on which there were four pegs (two upper pegs and two lower pegs) and 10 rings were hanging on each of the lower pegs (Figure 1). The lower pegs were positioned at the shoulder height of the participants, and the upper pegs were positioned $20 \mathrm{~cm}$ above the lower pegs. The participants were instructed to move as many rings as possible from the lower pegs to the upper pegs, and vice-versa, during a six-minute period. Blood pressure, $\mathrm{HR}$, and $\mathrm{SpO}_{2}$, as well as sensation of dyspnea and arm fatigue (as assessed by the modified Borg scale), were measured before and after each test. The participants performed two 6PBRTs, the second being performed after a 30-min interval or after the variables of interest had returned to their baseline values. Rest was allowed during the test, but the stopwatch was not stopped. If a participant needed to rest, he/she was instructed to resume the test as soon as possible (Figure 1). The outcome of the 6PBRT is the number of rings moved by the end of the test. Standardized phrases of encouragement were offered once every minute during the test.

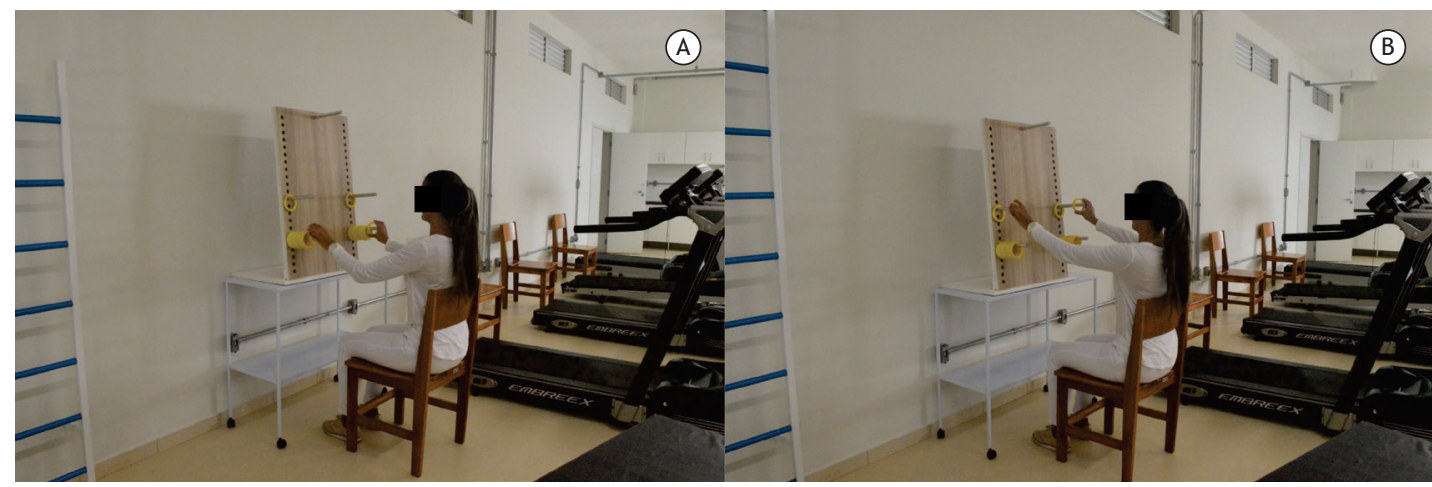

Figure 1. In $A$, a volunteer starting to move the rings from the lower to the upper pegs. In $B$, the same volunteer hanging the rings on the upper pegs. 


\section{Statistical analysis}

Data were tested for normality with the Shapiro-Wilk test, and the results were described as mean and standard deviation or as median and interquartile range. The lower limit of the $95 \%$ CI was adopted as the lower limit of acceptability for the reference values. ${ }^{(18)}$ The association of performance on the 6PBRT with age, gender, arm length, upper arm circumference of the dominant arm, forearm circumference of the dominant arm, and level of physical activity was assessed with Pearson's correlation test. On the basis of correlation analyses, we selected the variables that would be included in the multiple linear regression model. The criterion for inclusion was based on a $p$ value of $<0.05$, and the criterion for exclusion was based on a $\mathrm{p}$ value of $>0.10$. Multiple linear regression was performed in a stepwise fashion. The final model was determined by the adjusted coefficient of determination $\left(\mathrm{R}^{2}\right)$ and by statistical significance. The existence of multicollinearity was analyzed using variance inflation factors $>0.2$ and tolerance $<5$, and the distribution of residuals was examined for normality using quantile-quantile plots. Statistical analysis was performed with the Statistical Package for the Social Sciences, version 17.0 (SPSS Inc., Chicago, IL, USA), and the level of significance was set at $a=5 \%$.

\section{Sample size calculation}

According to Horn \& Pesce, ${ }^{(18)}$ sample sizes between 40 and 120 are robust when parametric statistical methods are used to determine reference values.

\section{RESULTS}

The study sample was a convenience sample of 104 individuals. There was no sample loss since all participants were able to perform the proposed test. None of the participants needed to interrupt the test, and, in all of them, the variables measured returned to baseline values within $30 \mathrm{~min}$ after the end of the test (on average, after $15 \mathrm{~min}$ ); therefore, the interval between the tests was $30 \mathrm{~min}$ for all participants. In each age group, the male/female ratio was controlled, being standardized to $1: 1$. The mean age of the participants was $56.44 \pm 15.72$ years, $52 \%$ being male and $98 \%$ being right-handed. The mean body mass index was $26.76 \pm 3.84 \mathrm{~kg} / \mathrm{m}^{2}$. In the sample as a whole, the mean number of rings moved was $376.19 \pm 79.33$ rings. All volunteers had normal pulmonary function. The anthropometric and demographic characteristics of the volunteers are presented in Table 1. Reference values for the 6PBRT were established for each age group ( $\rho=-0.58 ; p<0.05$; Table 2$)$, given that gender did not influence performance $(\rho=0.06 ; p=$ $0.503)$. The participants in the younger age groups performed better on the 6PBRT than did those in the older age groups (Tables 2 and 3), with a correlation of $r=-0.583(p<0.05)$.

The sample was classified as active by the HAP (80.65 \pm 11.21 points), and $69.2 \%$ of the participants considered themselves active, performing physical activities 3-5 times a week. The 6PBRT results showed a weak, positive correlation with the level of physical activity $(r=0.358 ; p<0.05)$ but did not correlate with arm length $(r=0.105 ; p=0.238)$; upper arm circumference $(r=-0.053 ; p=0.553)$; or forearm circumference ( $r=-0.007 ; p=0.938$; Table 3$)$.

The regression equation that enabled the construction of Table 3 with the reference values was as follows:

$6 \mathrm{PBRT}=676.34-(4.223 \times$ age $) ; \mathrm{R}^{2}=0.34$.

\section{DISCUSSION}

The present study presents reference values for the 6PBRT in healthy individuals $\geq 30$ years of age in

Table 1. Descriptive analysis for the sample as a whole $(\mathrm{N}=104){ }^{\mathrm{a}}$

\begin{tabular}{|c|c|}
\hline Variable & Result \\
\hline Age, years & $56.44 \pm 15.72$ \\
\hline $\mathrm{BMI}, \mathrm{kg} / \mathrm{m}^{2}$ & $26.76 \pm 3.84$ \\
\hline Dominant arm length, $\mathrm{cm}$ & $70.63 \pm 5.34$ \\
\hline $\begin{array}{l}\text { Upper arm circumference of the } \\
\text { dominant arm, cm }\end{array}$ & $28.31 \pm 3.24$ \\
\hline $\begin{array}{l}\text { Forearm circumference of the dominant } \\
\mathrm{arm}, \mathrm{cm}\end{array}$ & $25.22 \pm 2.82$ \\
\hline AAS & $80.78 \pm 11.29$ \\
\hline FVC, $\%$ of predicted & $94.52 \pm 14.07$ \\
\hline $\mathrm{FEV}_{1}, \%$ of predicted & $93.12 \pm 14.59$ \\
\hline $\mathrm{FEV}_{1} / \mathrm{FVC}, \%$ & $96.73 \pm 8.23$ \\
\hline
\end{tabular}

BMI: body mass index; and AAS: adjusted activity score (on the Human Activity Profile questionnaire). avalues presented as mean \pm SD.

Table 2. Descriptive statistics for performance (number of rings moved) on the six-minute pegboard and ring test, by age group.

\begin{tabular}{ccccc} 
Age group & $\mathbf{n}$ & Mean & SD & $95 \%$ Cl \\
\hline $30-39$ & 20 & 430.25 & 77.11 & $394.16-466.34$ \\
$40-49$ & 20 & 414.85 & 61.40 & $386.11-443.59$ \\
$50-59$ & 20 & 382.70 & 59.38 & $359.36-428.44$ \\
$60-69$ & 17 & 373.76 & 59.41 & $343.22-404.31$ \\
$70-79$ & 19 & 320.74 & 65.75 & $289.05-352.43$ \\
$>80$ & 08 & 265.00 & 47.38 & $225.39-304.61$ \\
\hline
\end{tabular}

Table 3. Correlation of the final six-minute pegboard and ring test score with dominant arm length, upper arm circumference of the dominant arm, forearm circumference of the dominant arm, level of physical activity, and age.

\begin{tabular}{lcc}
\multicolumn{1}{c}{ Variable } & $\mathbf{r}^{*}$ & $\mathbf{p}$ \\
Dominant arm length & 0.105 & NS \\
$\begin{array}{l}\text { Upper arm circumference of the } \\
\text { dominant arm }\end{array}$ & -0.053 & NS \\
$\begin{array}{l}\text { Forearm circumference of the } \\
\text { dominant arm }\end{array}$ & -0.007 & NS \\
Level of physical activity & 0.358 & 0.000 \\
Age & -0.583 & 0.000 \\
\hline
\end{tabular}

NS: not significant. *Pearson's correlation coefficient. 
Brazil. In addition, factors impacting the performance of this population on the 6PBRT were analyzed. These findings will be useful for clinical application, enabling comparison of results between healthy individuals and individuals with different health conditions.

The present study demonstrated that only age was a determinant of performance on the 6PBRT in both genders, younger individuals performing better on the test than did older individuals.

Arm length, upper arm circumference of the dominant arm, and forearm circumference of the dominant arm did not influence 6PBRT results. To our knowledge, this is the first study aimed at determining reference values for the 6PBRT in healthy adults and elderly individuals in Brazil.

The number of rings moved was higher among younger participants (30-49 years of age) than among older participants ( $\geq 80$ years). It is well established in the literature that aging affects muscle mass, strength, endurance, and motor coordination, including in healthy, physically active individuals. ${ }^{(18,19)}$ This may explain the findings of the present study, given that these variables are components of functional capacity. Another important point, demonstrated by Nyberg et al..(9) is that 6PBRT results correlate better with endurance than with arm muscle strength in individuals with COPD. According to the authors, this can be explained by the fact that the 6PBRT consists of small amplitude movements during which the individuals keep their shoulders flexed at $90^{\circ}$, throughout the test. Although the 6PBRT is less intense from a cardiorespiratory standpoint (unloaded test of short duration), it requires greater motor coordination.

Although gender is a predictor of performance on some functional tests, ${ }^{(20,21)}$ the present study found no such association. The lack of association between gender and 6PBRT results can be explained by the fact that the 6PBRT involves motor coordination, endurance, and manual dexterity rather than strength, which is one of the factors that most differentiates men from women in terms of physical capacity. ${ }^{(22,23)}$

The 6PBRT results showed a week correlation with the level of physical activity as assessed by the HAP, which corroborates the findings of Ohara et al. (24) This can be explained by the fact that the 6PBRT does not lead to a significant cardiorespiratory demand. Among patients with COPD, 6PBRT results correlate with arm ALD. ${ }^{(11)}$ Physical exercise is known to improve muscle flexibility, as well as to increase endurance and motor coordination, (24-27) but this was not observed here, because we conducted a cross-sectional study and there was no physical training followed by determination of whether there was improvement in performance on the 6PBRT.

Arm length, upper arm circumference of the dominant arm, and forearm circumference of the dominant arm did not correlate with the participant's performance on the 6PBRT, which shows that a better performance on the test does not depend on having long or short arms or having larger or smaller upper arm and forearm circumference. Janaudis-Ferreira et al.(28) evaluated the relationship of shoulder and elbow flexion strength with the total 6PBRT score and found a moderate to strong correlation between shoulder flexion strength and the 6PBRT $(r=0.41 ; p=0.016)$ and between elbow flexion strength and the 6PBRT ( $r=0.81$; $<0.0001$ ), which demonstrates that the muscles of these joints have an important relationship with 6PBRT results. These findings allow us to infer that, if there were an increase in upper arm and forearm circumference due to increased muscle mass, there would be an improvement in performance on the test; however, the present study did not assess arm muscle strength, which makes this comparison difficult.

One of the limitations of the present study is the small number of individuals older than 80 years, which compromises the generalizability of our findings to that age group. This is due to the fact that the population selected for the study should be healthy, without symptomatic disease or any disease that would limit their ability to perform the 6PBRT, which made us exclude some individuals $(n=10)$. However, the criteria for robustness and reliability in statistical analysis, such as the estimated sample size and achievement of the required number of individuals for each age group, ${ }^{(29)}$ were met. Another limitation is that we used convenience sampling, which may compromise the external validity of the study. However, this sampling method has been used in benchmark studies. ${ }^{(20,21)}$

In conclusion, the present study was able to determine reference values for the 6PBRT in healthy adults in Brazil. There was a correlation between 6PBRT results and age, given that the older the individuals, the worse they performed on the test. In view of these findings, we can consider using the 6PBRT in the assessment of arm function both in clinical practice and for research purposes. Since the 6PBRT is simple and easy to perform, its use can be extended to conditions leading to limitation of arm function.

\section{REFERENCES}

1. Couser JI Jr, Martinez FJ, Celli BR. Respiratory response and ventilatory muscle recruitment during arm elevation in normal subjects. Chest. 1992;101(2):336-40. https://doi.org/10.1378/ chest.101.2.336

2. Panka GF, Oliveira MM, França DC, Parreira VF, Britto RR, Velloso M. Ventilatory and muscular assessment in healthy subjects during an activity of daily living with unsupported arm elevation. Rev Bras Fisioter. 2010;14(4):337-44. https://doi.org/10.1590/S1413-

\section{3}

3. Holland AE, Hill CJ, Nehez E, Ntoumenopoulos G. Does unsupported upper limb exercise training improve symptoms and quality of life for patients with chronic obstructive pulmonary disease? J Cardiopulm Rehabil. 2004;24(6):422-7. https://doi.org/10.1097/00008483200411000-00010

4. de Souza GF, Castro AA, Velloso M, Silva CR, Jardim JR. Lactic acid levels in patients with chronic obstructive pulmonary disease 
accomplishing unsupported arm exercises. Chron Respir Dis 2010;7(2):75-82. https://doi.org/10.1177/1479972310361833

5. Miles DS, Cox MH, Bomze JP. Cardiovascular responses to upper body exercise in normals and cardiac patients. Med Sci Sports Exerc. 1989;21 (5 Suppl):S126-31. https://doi.org/10.1249/00005768198910001-00003

6. Takahashi T, Jenkins SC, Strauss GR, Watson CP, Lake FR. A new unsupported upper limb exercise test for patients with chronic obstructive pulmonary disease. J Cardiopulm Rehabil. 2003;23(6):430-7. https://doi.org/10.1097/00008483-20031100000007

7. Zhan S, Cerny FJ, Gibbons WJ, Mador MJ. Development of an unsupported arm exercise test in patients with chronic obstructive pulmonary disease. J Cardiopulm Rehabil. 2006;26(3):180-7. discussion 188-90.

8. Janaudis-Ferreira T, Beauchamp MK, Goldstein RS, Brooks D. How should we measure arm exercise capacity in patients with COPD? A systematic review. Chest. 2012;141(1):111-120. https://do. org/10.1378/chest.11-0475

9. Nyberg A, Törnberg A, Wadell K. Correlation between limb muscle endurance, strength, and functional capacity in people with chronic obstructive pulmonary disease. Physiother Can. 2016;68(1):46-53. https://doi.org/10.3138/ptc.2014-93

10. Lima VP, Velloso M, Almeida FD, Carmona B, Ribeiro-Samora GA, Janaudis-Ferreira T. Test-retest reliability of the unsupported upper limb exercise test (UULEX) and six-minute peg board ring test (6PBRT) in healthy adult individuals. Physiother Theory Pract 2018:34. Epub 2018 Jan 19. https://doi.org/10.1080/09593985.201 8.1425786

11. Takeda K, Kawasaki Y, Yoshida K, Nishida Y, Harada T, Yamaguchi K, et al. The 6-minute pegboard and ring test is correlated with upper extremity activity of daily living in chronic obstructive pulmonary disease. Int J Chron Obstruct Pulmon Dis. 2013:8:347-51. https://doi. org/10.2147/COPD.S45081

12. Cancelliero-Gaiad KM, Ike D, Soave L, Gomes EL, Dias FD, Costa D. Correlation between functional capacity and health-related quality of life in COPD: a case series. Fisioter Mov. 2014;27(4):505-14. https:/ doi.org/10.1590/0103-5150.027.004.AO02

13. McArdle WD. Fisiologia do Exercício--Nutrição, Energia Desempenho Humano. 7ed. Rio de Janeiro: Guanabara Koogan; 2011

14. Sagun G, Oguz A, Karagoz E, Filizer A, Tamer G, Mesci B. Application of alternative anthropometric measurements to predict metabolic syndrome. Clinics. 2014;69(5):347-53. https://doi.org/10.6061/ clinics/2014(05)09

15. I Consenso de Espirometria. J Bras Pneumol. 1996;22(3):164

16. Duarte AA, Pereira CA, Rodrigues SC. Validation of new brazilian predicted values for forced spirometry in caucasians and comparison with predicted values obtained using other reference equations. Bras Pneumol. 2007;33(5):527-35. https://doi.org/10.1590/S180637132007000500007
17. Souza AC, Magalhães Lde C, Teixeira-Salmela LF. Cross-cultura adaptation and analysis of the psychometric properties in the Brazilian version of the Human Activity Profile [Article in Portuguese] Cad Saude Publica. 2006;22(12):2623-36. https://doi.org/10.1590/ S0102-311X2006001200012

18. Horn PS, Pesce AJ. Reference intervals: an update. Clin Chim Acta. 2003;334(1-2):5-23. https://doi.org/10.1016/S0009-8981(03)00133-5

19. Hoogendam YY, van der Lijn F, Vernooij MW, Hofman A, Niessen WJ, van der Lugt $A$, et al. Older age relates to worsening of fine motor skills: a population-based study of middle-aged and elderly persons. Front Aging Neurosci. 2014;6:259. https://doi.org/10.3389/ fnagi.2014.00259

20. Hughes VA, Frontera WR, Wood M, Evans WJ, Dallal GE, Roubenoff $\mathrm{R}$, et al. Longitudinal muscle strength changes in older adults influence of muscle mass, physical activity, and health. J Gerontol A Biol Sci Med Sci. 2001;56(5):B209-17. https://doi.org/10.1093/ gerona/56.5.B209

21. Britto RR, Probst VS, de Andrade AF, Samora GA, Hernandes NA., Marinho PE, et al. Reference equations for the six-minute walk distance based on a Brazilian multicenter study. Brazilian J Phys Ther. 2013:17(6):556-63. https://doi.org/10.1590/S141335552012005000122

22. Dourado VZ, Guerra RL, Tanni SE, Antunes LC, Godoy I. Reference values for the incremental shuttle walk test in healthy subjects: from the walk distance to physiological responses. J Bras Pneumol. 2013:39(2):190-7. https://doi.org/10.1590/S180637132013000200010

23. Miller AE, MacDougall JD, Tarnopolsky MA, Sale DG. Gender differences in strength and muscle fiber characteristics. Eur J App Physiol Occup Physiol. 1993;66(3):254-62. https://doi.org/10.1007/ BF00235103

24. Ohara DG, Melo CS, Reis IM, Jamami M. Functional capacity assessment of upper limbs in healthy young adult subjects. Fisio Ter 2017;30(1):159-67. https://doi.org/10.1590/1980-5918.030.001.ao17

25. Miller MS, Callahan DM, Toth MJ. Skeletal muscle myofilament adaptations to aging, disease and disuse and their effects on whole muscle performance in older adult humans. Front Physiol. 2014;5:369. https://doi.org/10.3389/fphys.2014.00369

26. Cartee GD, Hepple RT, Bamman MM Zierath JR. Exercise Promotes Healthy Aging of Skeletal Muscle. Cell Metab. 2016;23(6):1034 1047. https://doi.org/10.1016/..cmet.2016.05.007

27. Hübner $L$, Voelcker-Rehage $C$. Does physical activity benefit motor performance and learning of upper extremity tasks in older adults?-A systematic review. Eur Rev Aging Phys Act. 2017;14:15. https://doi. org/10.1186/s11556-017-0181-7

28. Janaudis-Ferreira T, Hill K, Goldstein RS, Wadell K, Brooks D. Relationship and responsiveness of three upper-limb tests in patients with chronic obstructive pulmonary disease. Physiother Can. 2013;65(1):40-3. https://doi.org/10.3138/ptc.2011-49

29. Portney LG, Watkins MP. Foundations of Clinical Research: Applications to Practice, 3rd ed. New Jersey: Prentice Hall; 2009. 